\title{
Epidemiología y laboratorio: Una visión diferente de la salud pública en Chile
}

\author{
Julio García M. e Ingrid Heitmann G.
}

\section{Epidemiology and laboratory: a different point o view of public health in Chile}

The authors present an abridged history from their personal point of view of public health dealing with communicable diseases in Chile, in reference to an article previously published in Revista Chilena de Infectología. They do not agree with the mainly critical view of the author. They recognize that although there is a lot to be done on this matter, Chile has been a pioneer in Latin America in many policies relating to the control of these infections, having been recognized by international organisms. The relationship between the National Institute of Public Health, the Ministry of Health and the Laboratory Network, has strongly contributed along the years to concrete sanitary achievements in the field of transmissible diseases which are a pride for our country.

$\mathrm{E}$ videntemente la historia de la humanidad en relación a las enfermedades infecciosas está lejos de terminar. Sin embargo, cabe hacer presente que las preocupaciones manifestadas por el Dr. Cabello en su artículo: "Epidemiología y laboratorios: El eslabón perdido en los planes para estudiar y prevenir la enfermedades infecciosa en Chile" (Rev Chil Infect Vol 25, $N^{\circ} 2$, p. 14-16), acerca del "desarrollo de una estructura profesional encargada de la pesquisa de la enfermedad infecciosa a lo largo del territorio nacional sustentada en una red de laboratorios" no es un invento nuevo para Chile. Debemos mencionar que el 9 de septiembre de 1892 se creó en Chile el Instituto de Higiene dentro de la primera ley orgánica de la Higiene Pública en Chile.

En el año 1924 desaparece el Instituto de Higiene siendo reemplazado en 1929 por el Instituto Bacteriológico de Chile, que inicialmente ocupaba las mismas dependencias de su antecesor para trasladarse posteriormente a las dependencias de Maratón 1000. El primer Director del Instituto Bacteriológico fue el Dr. Rudolf Krauss, quien en 1913 había organizado el Instituto Carlos Malbrán en Argentina. El Dr. Krauss dio origen a la idea de un laboratorio de referencia y la constitución de redes de laboratorio al señalar que los laboratorios del Instituto actuarían "como una central" y los laboratorios provinciales "deberían ser organizados bajo la tutela del Instituto y para ello debían utilizarse los bacteriólogos-higienistas formados por la Escuela Nacional de Higiene dependiente del Instituto Bacteriológico".
Desde mediados de los 70 es claro que no existe el denominado "eslabón perdido" sino que el Instituto se desarrolló en plenitud como laboratorio nacional y de referencia y sus redes nacionales de laboratorios organizadas en el mismo período, pasaron a jugar un rol preponderante como brazo derecho de Epidemiología del Ministerio de Salud (MINSAL) en la vigilancia y control de las enfermedades infecciosas en Chile. En los años 90, esta estructura fue reforzada por el desafío que implica la aparición de enfermedades emergentes y re-emergentes (infección por hantavirus, dengue, influenza aviar, infección por virus del Nilo Oeste, infección por virus de inmunodeficiencia humana, fiebre amarilla, vigilancia de resistencia bacteriana y de anti-retrovirales, síndrome hemolítico urémico, etc).

Profesionales de esta Institución, desde 1974 y hasta la fecha, integran permanentemente comisiones de trabajo multidisciplinarias con el MINSAL (tanto en el área de las personas como en Ambiente) para el enfoque de las problemáticas infecto-contagiosas endémicas, emergentes y re-emergentes. Podemos destacar como hitos recientes:

- Un laboratorio de Genética Molecular apoya desde la perspectiva de construcción de bases de datos genéticas permanentes de los principales agentes infecciosos que circulan en el país y ha tenido un rol importante en el estudio de la introducción de agentes virales al territorio tales como hantavirus $\mathrm{y}$ dengue, logrando en ambos casos la secuenciación completa del material genético. También, realiza un importante trabajo en el estudio de nuevas varian-
Instituto de Salud Púlica de Chile

Departamento Laboratorio Biomédico Nacional (JGM) Dirección (IHG)

(El presente artículo es una réplica al Comentario de Felipe Cabello: "Epidemiología y laboratorios: El eslabón perdido en los planes para estudiar y prevenir la enfermedades infecciosa en Chile" publicado en Rev Chil Infect 2008; 25 (1): 14-16. El texto ha sido abreviado por el Editor rescatando los conceptos medulares en esta réplica).

Correspondencia a: Julio García Moreno jgarcia@ispch.cl 
tes de los virus influenza y rubéola. Esta sección cuanta con equipamiento de última generación y participa en redes internacionales en temas como multi-resistencia de micobacterias con bases de datos comunes para América Latina y España. Otra red es Pulsenet para electroforesis de campo pulsado para infecciones transmitidas por alimentos (ETA) la que tiene cobertura mundial (desde 1992 a la fecha).

- Implementación de técnicas diagnósticas para infección por virus de hepatitis C (1995).

- Certificación del primer caso humano de rabia por variante 4 (murciélago) (1996).

- Implementación de técnicas diagnósticas para infección por hantavirus (1997).

- Primer aislado de hantavirus desde un caso de síndrome pulmonar (1999).

- El ISP es nombrado Laboratorio Subregional de Referencia (OMS) para estudios de sensibilidad de micobacterias (2000).

- Implementación de un laboratorio de referencia en carga viral de VIH (2000).

- Implementación de técnicas diagnósticas de dengue (2000).

- Acreditación de laboratorio de detección de anticuerpos anti-rábicos para mascotas a la comunidad europea (2002).

- Implementación de diagnóstico de género Plasmodium (Malaria). A la fecha se han implementado dos técnicas rápidas por métodos de inmunocaptura y detección del parásito por técnicas de Biología Molecular, RPC (2005).

- Inicio de la vigilancia de infección por rotavirus (2006).

- Implementación de la vigilancia de virus papiloma humano (2006).

- Creación de un laboratorio de Referencia en Entomología, con financiamiento especial del MINSAL, para realizar sus actividades que van en apoyo del Programa de erradicación de Triatoma infestans (vinchuca) y el estudios de las especies de culícidos de importancia médica, con especial atención a aquellas potenciales transmisoras de malaria, fiebre amarilla y dengue (2006).

- Implementación de vigilancia de infecciones por Staphylococcus aureus resistentes a meticilina, adquiridas en la comunidad (2007).

- Creación del laboratorio de infecciones bacterianas emergentes y zoonosis (2008).

Es evidente que nos falta mucho por avanzar en estas materias, somos los primeros en reconocerlo, de hecho, en medicina nunca se alcanza el óptimo deseado por los especialistas (incluso en los países económicamente más prósperos). La suspensión de la demo- cracia, independientemente de lo lamentable que ello fue, no significó "una fragmentación de estas actividades" ni "un golpe fatal al incipiente desarrollo de estos sistemas", basta ver las actividades desarrolladas por el Instituto Bacteriológico, el Sistema Nacional de Laboratorios creado en 1974 y el Instituto de Salud Pública de Chile (ISP) creado en 1980, en que se concreta un laboratorio nacional de referencia y su trabajo en equipo con el MINSAL, para entender que no nos "fragmentamos ni sufrimos un golpe fatal". Ello no significa que los logros fueran fáciles y por ello son aún más significativos.

En el caso de meningitis virales causales de brotes de meningitis en el país, han sido tipificados por el ISP, con datos publicados en el Boletín Epidemiológico del MINSAL y en Revista Chilena de Infectología (1994), como resultado del trabajo conjunto de las redes locales, epidemiólogos de los Servicios de Salud afectados, SEREMI (Secretarías Regionales Ministeriales), MINSAL y el ISP.

Respecto a poliomielitis y vigilancia de parálisis fláccida aguda, Chile es un modelo medido a través de los indicadores que utiliza la OPS, siendo repetidamente destacado por dicha organización en encuentros regionales en la materia. Recientemente el Laboratorio de Poliovirus del ISP fue acreditado por la OPS/OMS como Laboratorio Nacional e incorporado, como miembro de red mundial de laboratorios de apoyo, a la erradicación del virus polio ya que cumplió satisfactoriamente los criterios utilizados para evaluar el desempeño de las actividades de la Red de Laboratorios de la OPS/OMS que apoyan el programa de erradicación de la polio en el mundo. Este reconocimiento incluye la participación del Laboratorio de Cultivos Celulares.

Respecto a infección por hantavirus, el ISP, en su carácter de laboratorio nacional y de referencia, implementó en octubre del año 1997 el primer Laboratorio de Enfermedades Infecciosas Emergentes en nuestro país, con altos niveles de bioseguridad. Esto permitió a nuestro país, contar con el diagnóstico de infección por hantavirus desde esa fecha y realizar, en el año 2000, el primer aislado mundial de hantavirus desde un paciente con síndrome cardiopulmonar por hantavirus (Emerg Infect Dis 2002 Jul; 8 (7): 657-61). El virus posteriormente fue secuenciado (Biol Res 2003; 36: 201-10) y entregado a la comunidad científica nacional e internacional como un aporte al desarrollo e investigación científica este tema. Actualmente, el ISP es quien confirma todos los casos sospechosos del país. Realizamos el diagnóstico en casos o contactos por la detección de anticuerpos (IgM-IgG) y por otros métodos moleculares, también realizamos secuenciación 
viral para determinar la variabilidad genética del virus y hemos desarrollado tecnologías moleculares para el diagnóstico precoz de la enfermedad.

El ISP ha colaborado en diversos estudios de investigación, entre los que figuran el proyecto de "Hantavirus: Ecología y enfermedad” de la Universidad de Nueva México y la Universidad Católica de Chile (19992003) en la determinación de anticuerpos neutralizantes anti-virus Andes. En los años 2003-2004 patrocinó el proyecto FONDECYT:”Caracterización biológica del hantavirus humano aislado en Chile" y también se han realizado diversos estudios colaborativos con otras instituciones como el Instituto Malbrán de Buenos Aires, Argentina, universidades nacionales y el Departamento de Epidemiología del MINSAL. Además se han desarrollado estudios de reservorios en diferentes regiones del país, en conjunto con la División de Salud del Ambiente del MINSAL, las SEREMIS y la Facultad de Medicina Veterinaria de la Universidad de Chile. Estos estudios de reservorios también han permitido el estudio de leptospirosis en los roedores.

El Laboratorio de Enfermedades Virales Emergentes, que tenía un nivel de seguridad cercano a nivel 3, aprobado para trabajo con hantavirus, ha sido remodelado el año 2007, encontrándose finalizado este año. El objetivo de este proyecto es cumplir las actuales normas internacionales y ha sido revisado por expertos OPS que garantizan que se cumplen las exigencias de bioseguridad, controles de acceso y protección de las personas y el ambiente. Esto permite mantener el cultivo de hantavirus y realizar aislamiento viral de otros agentes emergentes como es el caso de la preparación a una eventual pandemia de influenza. Además del ISP, el diagnóstico de infección por hantavirus se efectúa en dos otros centros reconocidos por el MINSAL: Universidad Católica y Universidad Austral de Valdivia. El diagnóstico específico en el ISP se entrega antes de de 72 horas hábiles y, en muchos casos, se entrega antes de las 48 hrs.

De esta forma, sin considerarnos la única instancia nacional en esta materia, el rol del ISP en conjunto con otras dependencias del Ministerio de Salud, ha sido fundamental para la prevención, vigilancia, diagnóstico y control de hantavirus en nuestro país, como también en el desarrollo de líneas de investigación en la materia.

Con estos breves antecedentes creemos que es difícil sostener que en el país el estudio de esta materia "parece ser limitado en herramientas epidemiológicas y microbiológicas" y que "no existe un programa sistematizado y una red de laboratorios” para enfrentar el problema. Obviamente todo puede mejorarse y tenemos deficiencias y desafíos por superar, pero no es apropiado desconocer los esfuerzos que se están desarrollando en un país en que los recursos en salud son escasos y siempre se deben focalizar por prioridades e impacto, teniendo presente el uso alternativo de los recursos disponibles. Este enfoque es primordial para manejar las problemáticas de salud pública en todos los países del mundo (incluso en los más desarrollados). Respecto a comparar la letalidad en Chile pese a que son similares con las cifras de los Estados Unidos de Norteamérica (35\% en E.U.A. y 37\% en Chile) no es un tema simple, debemos recordar que los virus son diferentes, en Chile tenemos en virus Andes y los presentes en E.U.A. son otros (Sin Nombre, Bayou, New York, etc). Pese a no disponerse de vacunas o tratamientos específicos para esta enfermedad, la existencia de un sistema de alerta temprana y una red de laboratorios vigilante con derivación inmediata a centros clínicos especializados de mayor complejidad ha permitido mantener estable la letalidad y la incidencia. Las acciones educativas que se han efectuado han tenido un impacto en la morbilidad, dado que nuestra población tiene una cultura de "escuchar e internalizar" las advertencias del MINSAL (prueba de ello son las coberturas de las campañas de vacunación desde su inicios y el respeto a las recomendaciones que implican cambios de conductas, lo cual ha llevado a la erradicación de sarampión, polio y otras enfermedades, incluso antes que países más desarrollados).

En el caso de Vibrio parahaemolyticus que aparece en Chile como un agente de diarrea aguda en los años 1997-8, en Antofagasta, durante un período de gran actividad de la corriente del niño, posteriormente hay un segundo brote en la Región de Los Lagos el 2004 y un tercer brote a contar del 2005 en que el brote es más prolongado y de mayor magnitud. Frente a este agente, el ISP ha mantenido el mismo sistema de vigilancia de laboratorio que se estableció durante el brote de cólera en que, en toda la red del país se efectúa, en forma aleatoria, la búsqueda de Vibrio sp en casos de diarrea aguda, tanto en niños como adultos, derivando los aislados sospechosos al ISP para confirmación (Circular $\mathrm{N}^{\circ}$ 4F/03 del MINSAL 12.01.98). Lo anterior ha permitido un oportuno diagnóstico presuntivo en el nivel local y una rápida confirmación en el ISP- debe tenerse presente que no se ha descrito en el mundo una forma de erradicar este agente. Cabe recordar que los primeros casos de $V$. parahaemolyticus con toxina $\mathrm{TDH}$ fueron diagnosticados en forma oportuna por esta misma Institución. En Chile V. parahaemolyticus es objeto de vigilancia de laboratorio en forma oficial desde el año 2000, con la publicación del Reglamento sobre Notificación de Enfermedades Transmisibles de Declaración Obligatoria N 712/2000 y 158/2004 del 
MINSAL, por lo cual los laboratorios clínicos, públicos y privados que identifiquen el agente están obligados a notificarlo al ISP. Además de ello, desde el 2005 los laboratorios de Ambiente de las SEREMI mantienen sistemas de vigilancia en los terminales pesqueros principales del país, la cual reconocemos que es necesario reforzar por falta de recurso humano y capacidad a analítica de los laboratorios de ambiente locales.

Cabe destacar que, frente a la situación de otros países que han sufrido el flagelo del cólera, Chile se defendió adecuadamente frente al brote de 1991 actuando en forma coordinada el ISP, MINSAL, Servicios de Salud, DISAM, SEREMIs, red nacional de laboratorios, etc. Aquí tampoco hubo "una estructura embrionaria o inexistente”. Cabe destacar que, aunque obviamente el aspecto fino de laboratorio a nivel molecular es un elemento importante hacia el control y seguimiento de una enfermedad infecciosa, sin embargo, para todo aquel que tenga experiencia epidemiológica de la llamada "suelas rotas", sabe que el "dictum: comer pescados y mariscos bien cocidos" no es banal, sino que por el contrario, este tipo de apoyo comunicacional con mensajes sencillos y directos, enfocados a aspectos claves para cortar la cadena de infección, suelen ser altamente efectivos en la práctica, para disminuir precozmente la morbilidad de la infección. Esto se comprobó en el caso de cólera en Chile, dengue en Isla de Pascua y tantas otras situaciones epidemiológicas. En el caso del cólera, este simple aforismo llevó a la disminución de hepatitis, fiebre tifoidea y otras patologías de igual fuente (un año después del inicio del brote, en la Región Metropolitana la fiebre tifoidea y hepatitis presentaban cifras entre 7 a 8 veces menores que las previas).

Finalmente un viejo salubrista quiere decir como Pasteur: "Nous avons une passion supérieure, c'est la verité”.

\section{Resumen}

Los autores, en referencia a un artículo anterior en esta revista, hacen un resumen de su propia perspectiva histórica acerca del manejo de la salud pública en Chile en relación a enfermedades transmisibles, que no coincide con los planteamientos básicamente críticos efectuados por el autor de dicho artículo. Se reconoce que existe mucho camino por andar en esta materia, pero que los esfuerzos realizados en Chile son muy significativos y no pueden desconocerse, incluso muchos resultan pioneros o líderes en América Latina, lo cual ha sido reconocido reiteradamente por los organismos internacionales del sector. La relación entre el Laboratorio Nacional y de Referencia (Instituto de Salud Pública de Chile), el Ministerio de Salud (Epidemiología y Disam) y la red de laboratorios, ha contribuido fuertemente a lo largo de muchos años, a la concreción de logros sanitarios que nos enorgullecen en el ámbito de las infecciosas transmisibles. 